\title{
CARBON IN CONDENSED HYDROCARBON PHASES, STEELS AND CAST IRONS
}

\section{Extended Abstract:}

The article presents a review of studies carried out mainly by the researchers of the Ufa State Petroleum Technological University, which are aimed at detection of new properties of carbon in such condensed media as petroleum and coal pitches, steels and cast irons. Carbon plays an important role in the industry of construction materials being a component of road and roof bitumen and setting the main mechanical properties of steels.

It was determined that crystal-like structures appear in classical glass-like substances - pitches which contain several thousands of individual hydrocarbons of various compositions. That significantly extends the concept of crystallinity. In structures of pitches, the control parameter of the staged structuring process is paramagnetism of condensed aromatic hydrocarbons.

Fullerenes were detected in steels and cast irons and identified by various methods of spectrometry and microscopy. Fullerene $C_{60}$, which contains 60 carbon atoms, has diameter of $0,7 \mathrm{~nm}$ and is referred to the nanoscale objects, which have a significant influence on the formation of steel and cast iron properties.

It was shown that fullerenes appear at all stages of manufacture of cast irons; they are formed during introduction of carbon from the outside, during crystallization of metal in welded joints. Creation of modified fullerene layers in steels makes it possible to improve anticorrosion and tribological properties of structural materials. At the same time, outside diffusion of carbon from the carbon deposits on the metal surface also leads to formation of additional amount of fullerenes. This creates conditions for occurrence of local microdistortions of the 
structure, which lead to occurrence of cracks. Distribution of fullerenes in iron matrix is difficult to study as the method is labor-intensive, it requires dissolution of the matrix in the hydrofluoric acid and stage fullerene separation with further identification by spectral methods.

Key words: carbon, fullerenes, pitches, steels, cast irons, mass spectrometry, IR spectrometry, crystallization.

DOI: dx.doi.org/10.15828/2075-8545-2017-9-6-111-128

MACHINE-READABLE INFORMATION ON CC-LICENSES (HTML-CODE) IN METADATA OF THE PAPER

$<$ a rel="license" href="http://creativecommons.org/licenses/by/4.0/" $><$ img alt="Creative Commons License" style="borderwidth:0" src="https://i.creativecommons.org/1/by/4.0/88x31.png" $/></ \mathrm{a}><$ br $/><$ span xmlns:dct="http://purl.org/dc/ terms/" href="http://purl.org/dc/dcmitype/Text" property="dct:title" rel="dct:type" $>$ Carbon in condensed hydrocarbon phases, steels and cast irons. $</$ span $>$ by $<$ a xmlns:cc $="$ http://creativecommons.org/ns\#" href="Nanotehnologii v stroitel'stve = Nanotechnologies in Construction. 2017, Vol. 9, no. 6, pp. 111-128. DOI: dx.doi.org/10.15828/2075-8545-2017-9-6-111128 " property="cc:attributionName" rel="cc:attributionURL" $>$ Gafarova V.A. $</$ a $>$ is licensed under a $<$ a rel="license" href="http://creativecommons.org/licenses/by/4.0/" $>$ Creative Commons Attribution 4.0 International License $</ \mathrm{a}>$. $<$ br />Based on a work at <a xmlns:dct="http://purl.org/dc/terms/" href=" http://nanobuild.ru/en_EN/nanobuild-6-2017/" rel="dct:source" $>$ http://nanobuild.ru/en_EN/nanobuild-6-2017/ $</ \mathrm{a}>.<\mathrm{br} />$ Permissions beyond the scope of this license may be available at $<$ a xmlns:cc="http://creativecommons.org/ns\#" href="gafarova.vika@bk.ru" rel="cc:morePermissions" $>$ gafa rova.vika@bk.ru</a>.

\section{References:}

1. Fialkov A.S. Uglerod, mezhsloevye soedineniya i kompozity na ego osnove [Carbon, interlayer connections and composite materials based on it]. Moscow: Aspect Press, 1997. 718 p. (In Russian).

2. Sidorova L.N., Yurovskaya M.A., Borshchevskij A.Ya., Trushkov I.V., Ioffe I.N. Fullereny [Fullerenes]. Moscow, Publishing house «Ekzamen», 2005. 688 p. (In Russian).

3. Gavrilyuk V.G. Raspredelenie ugleroda v stali [Distribution of carbon in steel]. Kyiv, Naukova dumka, 1987, 208 p. (In Russian).

4. Gimaev R.N., Kuzeev I.R., Abyzgildin Yu.M. Neftyanoj koks [Petroleum coke]. Moscow, 1992. 80 p. (In Russian).

5. Kuzeev I.R., Sharafiev R.G., Abyzgil'din Yu.M., Kretinin M.V. Crystallization of petroleum carbon on metal surface. Chemistry and Technology of Fuels and Oils, 1984. Vol. 20. № 1. pp. 29-32. (In Russian). 
6. Bayazitov M.I., Vasiliev A.N., Gafarova V.A., Kuzeev I.R., Nikiforova D.K. Formirovanie priznakov kristallicheskih tel $\mathrm{v}$ potencial'no amorfnyh sistemah [Formation of crystalline bodies traces in potentially amorphous systems]. Izvestiya of higher educational institutions. Oil and gas. [Higher Educational Institutions News. Oil and Gas]. 2014. № 5. P. 82-86. (In Russian).

7. Andreeva L.N., Aleksandova S.Ya., Tsyro L.V., Unger F.G. Fizika obrazovanija kolloidov neftjanyh dispersnyh sistem. Jelementy spinovoj himii [Physics of oil dispersion colloids formation. Elements of spin chemistry]. Izvestiya of higher educational institutions. Oil and gas. [Higher Educational Institutions News. Oil and Gas]. 2009, № 4, p. 101-107. (In Russian).

8. Kuzeev I.R., Khairudinov I.R., Ibragimov I.G., Abyzgildin Yu.M., Khabibullin R.L. Sostav spiralevidnyh struktur pri kristallizacii neftjanogo ugleroda na poverhnosti metalla [Composition of helical structures in crystallization in petroleum carbon on a metal surface]. Himija i tehnologija topliv i masel [Chemistry and Technology of Fuels and Oils]. 1984. № 11. p. 29. (In Russian).

9. Kuzeev I.R., Khairudinov I.R., Ibragimov I.G., Abyzgil'din Yu.M., Khabibullin R.L. Composition of helical structures in crystallization in petroleum carbon on a metal surface Himija i tehnologija topliv i masel [Chemistry and Technology of Fuels and Oils]. 1985. Vol. 20. № 11. p. 559-561.

10. Khairudinov I.R., Kuzeev I.R., Ibragimov I.G., Unger F.G. Sostav otlozhenij koksosmolistyh produktov na metallicheskoj poverhnosti [Composition of coke-resinous products sediments on a metal surface]. Izvestiya of higher educational institutions. Series: Chemistry and chemical technology. 1986. Vol. 29. № 12. p. 47-51. (In Russian).

11. Kuzeev I.R., Khairudinov I.R., Abyzgildin Yu.M. Formirovanie neftjanyh uglerodistyh veshhestv i ih vzaimodejstvie s metallicheskoj poverhnost'ju [Formation of petroleum carbon substances and their interaction with a metal surface]. Himija tverdogo topliva [Chemistry of solid fuel]. 1987. № 2. p. 142. (In Russian).

12. Mukhametzianov I.Z., Kuzeev I.R., Abyzgildin Yu.M. Fraktal'nye struktury pri karbonizacii neftjanogo syr'ja [Fractal structures during carbonization of crude oil]. Himija tverdogo topliva [Chemistry of solid fuel]. 1990. № 6. p. 91-94. (In Russian).

13. Kulikov D.V., Kuzeev I.R. Solid petroleum residue as macroscopic model systems for the study of microstructure in metal materials. Materials Science and Engineering: A. 1997. Vol. 234-236. p. 949-952.

14. Kuzeev I.R., Mukhametzianov I.Z. Fraktal'naja struktura paramagnitnyh agregatov neftjanyh pekov [Fractal structure of petroleum pitch paramagnetic aggre- 
gates]. Kolloidnyj zhurnal [Colloid jounal]. 1991. Vol. 53. № 4. p. 762-766. (In Russian).

15. Mukhametzyanov I.Z., Kuzeev I.R., Voronov V.G., Spivak S.I. Structural organization of petroleum disperse systems. Doklady Physical Chemistry. 2002. Vol. 387. № 1-3. p. 284-286.

16. Kuzeev I.R., Ibragimov I.G., Bayazitov M.I., Khayrutdinov I.R. Osobennosti diffuzii ugleroda iz neftjanogo koksa $v$ metall [Peculiarites of diffusion of carbon from petroleum coke to metal]. Himija i tehnologija topliv i masel [Chemistry and technology of fuels and oils]. 1986. № 6. p. 13-14. (In Russian).

17. Kroto H.W., Heath J.R., O'Brien S.C., Curl R.F. \& C. Smalley R.E. Buckminsterfullerene // Nature 318:162-3. 1985.

18. Zakirnichnaya M.M., Kuzeev I.R. Opredelenie formy svobodnogo ugleroda v uglerodistyh splavah [Determination of form of free carbon in carbon alloys]. In Proc. of XXXXVII Scientific and technical conference of students, postgraduates and young scientists. 1996. p. 166. (In Russian).

19. Kuzeev I.R., Zakirnichnaya M.M., Samigullin G.Kh., Mekalova N.V. Fullerennaja model' struktury zhelezo-uglerodistyh splavov [Fullerene model of iron-carbon alloys]. In the collection of works: Synergetics, structure and properties of materials, self-organizing technologies. Symposium. 1996. p. 208. (In Russian).

20. Cox D.M., Reichmann K.C., Kaldor A.P. // Chem. Soc. 1988. Vol. 10. p. 1588.

21. Ivanova V.S., Kuzeev I.R., Zakirnichnaya M.M. Fullereny v chugune [Fullerenes in cast iron]. Materialovedenie [Materials science]. 1998. № 2. p. 5-14. (In Russian).

22. Ivanova V.S., Kuzeev I.R., Kozitsky D.V., Zakirnichnaya M.M. O samopodobii fullerenov, obrazujushhegosja v strukturah produktov termicheskogo isparenija grafita, shungita i vysokouglerodistoj stali [On self-similarity of fullerenes forming in structures of products of thermal evaporation of graphite, shungite and high-carbon steel]. Perspektivnye materialy [Advanced materials]. 1998. № 1. p. 5-15. (In Russian).

23. Zakirnichnaya M.M. Obrazovanie fullerenov v uglerodistyh stalyah i chugunah pri kristallizacii i termicheskih vozdejstviyah [Fullerene formation of in carbon steels and cast irons during crystallization and thermal influences]. Ufa, Publishing house «Gilem», 2002. 180 p. (In Russian).

24. Kuzeev I.R., Zakirnichnaya M.M., Godovsky D.A. Obrazovanie fullerenov v strukture chugunov pri pervichnoj kristallizacii i domennom processe [Fullerene formation in cast iron structure during the first crystallization and blast furnace process]. In the collection of works: Fractals and applied synergetics. Proceedings of International interdisciplinary symposium. 1999. p. 187-189. (In Russian). 
25. Zakirnichnaya M.M., Kuzeev I.R., Kornilov V.M., Lachinov A.N. Migracija i obrazovanie fullerenovyh struktur na razlichnyh stadijah poluchenija zhelezo-uglerodistyh splavov [Migration and formation of fullerene structures at various stages of iron-carbon alloys manufacturing]. Geologija. Izvestija Otdelenija nauk o Zemle i prirodnyh resursov [Geology. News of Department of Earth sciences and natural resources. Academy of Sciences of the Republic of Bashkortostan]. 2001. № 6 . p. 39-49. (In Russian).

26. Kuzeev I.R., Zakirnichnaya M.M., Tkachenko O.I., Godovsky D.A. Izuchenie fullerenov v nauglerozhennom sloe, poluchennom pri cementacii [Study of fullerenes in carburized layer obtained during cementation]. Tehnika na poroge HHI veka [In the collection of works: Technics into the XXI century]. 1999. p. 176177. (In Russian).

27. Zakirnichnaya M.M., CHirkova A.G., Kuzeev I.R. Izmenenie struktury i svojstv metalla trub zmeevikov pechej piroliza v processe jekspluatacii [Change of structure and properties of pyrolysis furnace coil pipes metal in the process of operation]. Izvestija vysshih uchebnyh zavedenij. Neft' i gaz. [Higher Educational Institutions News. Oil and Gas]. 1998. № 2. C. 87-92. (In Russian).

28. Nikiforova D.K., Gafarova V.A., Vasiliev V.V., Kuzeev I.R. Izmenenie fiziko-mehanicheskih svojstv stali pri diffuzionnom nasyshhenii uglerodom poverhnostnogo sloja [Change of physical-mechanical properties of steel during carbon diffusion saturation of surface layer]. Promyshlennaja bezopasnost' na vzryvopozharoopasnyh i himicheski opasnyh proizvodstvennyh ob'ektah. Materialy VIII nauchnoprakticheskoj konferencii [In the collection of works: Industrial safety at explosive and flammable and chemically hazardous production facilities. Proceedings of VIII Scientific and practical conference]. 2014. p. 158-160. (In Russian).

29. Kuzeev I.R., Popova S.V., Gimalova M.R. Modificirovanie poverhnostnogo sloja stali $20 \mathrm{~s}$ pomoshh'ju fullerenov [The modification of carbon steel surface layer with fullerenes participation]. Neftegazovoe delo [Oil and Gas Engineering]. 2012. Vol. 10. № 1. p. 185-190. (In Russian).

30. Gabdulina M.R., Kuzeev I.R., Nikiforova D.K., Gabdullin M.F. Formirovanie metallofullerenovogo poverhnostnogo sloja s cel'ju passivacii poverhnosti v uglerodistyh staljah [Formation of metal fullerene surface layer with the aim of surface passivation in carbon steels]. Neftegazovoe delo [Oil and Gas Engineering]. 2014. № 3. p. 310-328. (In Russian).

31. Zakirnichnaya M.M., Kuzeev I.R., Tkachenko O.I. Raspredelenie fullerenov po zonam svarnogo soedinenija [Fullerenes distribution on welded joint zones]. Svarochnoe proizvodstvo [Welding production]. 1999. № 11. p. 23. (In Russian). 
32. Zakirnichnaya M.M., Kuzeev I.R., Tkachenko O.I. Obrazovanie fullerenov v processe diffuzii ugleroda v strukturu stali [Fullerenes formation in the process of carbon diffusion to the steel structure]. Izvestija vysshih uchebnyh zavedenij. Neft' i gaz. [Higher Educational Institutions News. Oil and Gas]. 2012. №2. p. 112-119. (In Russian).

33. Chirkova A.G., Kuzeev I.R., Popova S.V., Vasiliev A.N. Izmenenie naprjazhennodeformirovannogo sostojanija zmeevikov pechej piroliza $v$ processe jekspluatacii [Change of stressed-deformed state of pyrolysis furnace coils in the process of operation]. Bashkirskij himicheskij zhurnal [Bashkir Chemistry Journal]. 2011. Vol. 18. № 1. p. 78-82. (In Russian).

34. Kuzeev I.R., Popova S.V., Vasiliev A.N. Izuchenie zakonomernosti diffuzii ugleroda $\mathrm{v}$ poverhnostnyj sloj stali $12 \mathrm{H} 18 \mathrm{~N} 10 \mathrm{~T}$ [Study of regularity of carbon diffusion to the steel 12X18H10T surface layer]. Lit'e i metallurgija [Casting and metallurgy]. 2012. № 3. p. 346-348. (In Russian).

35. Khisaeva Z.F., Kuzeev I.R. Modificirovanie poverhnosti zmeevikov trubchatyh pechej dlja zashhity ot nauglerozhivanija i koksoobrazovanija [Modification of pipe furnace coils surface for protection from carbonization and coke formaion]. Neftegazovoe delo [Oil and Gas Engineering]. 2003. № 2. p. 13. (In Russian).

36. Kuzeev I.R., Popova S.V., Savicheva Yu.N. Sposob identifikacii fullerenov $\mathrm{C}_{60}$ i $_{70}$ $\mathrm{v}$ staljah i chugunah [Method of fullerenes c60 and c70 identification in steels and cast irons]. Invention patent RUS 2411182 08.07.2009 (In Russian).

37. Makarova T.L. Magnitnye svojstva uglerodnyh struktur [Magnetic properties of carbon structures]. Fizika i tehnika poluprovodnikov [Physics and technics of semiconductors]. 2004. Vol. 38. Issue 6. p.641-664. (In Russian).

\section{DeAR COLLEAGues!}

THE REFERENCE TO THIS PAPER HAS THE FOLLOWING CITATION FORMAT:

Gafarova V.A. Carbon in condensed hydrocarbon phases, steels and cast irons. Nanotehnologii v stroitel'stve $=$ Nanotechnologies in Construction. 2017, Vol. 9, no. 6, pp. 111-128. DOI: dx.doi.org/10.15828/2075-8545-2017-9-6-111-128. (In Russian). 
УДК 669.017 : $621.791,621.74: 620.18$

Автор: ГАФАРОВА Виктория Александровна, аспирант каф. «Технологические машины и оборудование» ФГБОУ ВО «УГНТУ»; ул. Космонавтов 1, г. Уфа, Россия, 450062, gafarova.vika@bk.ru

\section{УГЛЕРОД В КОНДЕНСИРОВАННЫХ УГЛЕВОДОРОДНЫХ ФАЗАХ, СТАЛЯХ И ЧУГУНАХ}

АННОТАЦИЯ К СТАТЬЕ (АВТОРСКОЕ РЕЗЮМЕ, РЕФЕРАТ):

В статье представлен обзор исследований, проведенных, в основном, сотрудниками Уфимского государственного нефтяного технического университета, направленных на выявление новых свойств углерода в конденсированных средах, таких, как нефтяные и каменноугольные пеки, стали и чугуны. Углерод играет важную роль в индустрии строительных материалов, входя в состав дорожных и кровельных битумов, задавая основные механические свойства сталей. Обнаружено, что в классических стеклоподобных веществах - пеках, содержащих несколько тысяч индивидуальных углеводородов различного строения, возникают кристаллоподобные структуры в макромасштабе, что существенно расширяет понятие кристалличности. В структурах пеков управляющим параметром процесса ступенчатого структурирования является парамагнетизм конденсированных ароматических углеводородов. В сталях и чугунах обнаружены фуллерены и идентифицированы различными методами спектрометрии и микроскопии. Фуллерен C60, содержащий 60 атомов углерода, имеет диаметр 0,7 нм и относится к нанообъектам, оказывающим существенное влияние на формирование свойств сталей и чугунов. Показано, что фуллерены присутствуют на всех стадиях получения чугунов, образуются при внедрении углерода извне, кристаллизации металла в сварных соединениях. Создание модифицированных фуллереновых слоев в сталях позволяет улучшить антикоррозионные и трибологические свойства конструкционных материалов. В то же время диффузия углерода извне из углеродистых отложений на поверхности металла также приводит к образованию дополнительного количества фуллеренов. При этом создаются условия для возникновения локальных микроискаже- 
ний структуры, приводящих к образованию трещин. Трудности в изучении распределения фуллеренов в матрице железа заключаются в трудоемкости метода, который требует растворения матрицы в плавиковой кислоте и стадийного выделения фуллеренов с последующей идентификацией спектральными методами.

Ключевые слова: углерод, фуллерены, пеки, стали, чугуны, массспектрометрия, ИК-спектрометрия, кристаллизация.

DOI: dx.doi.org/10.15828/2075-8545-2017-9-6-111-128

МАШИНОЧИТАЕМАЯ ИНФОРМАЦИЯ О СС-ЛИЦЕНЗИИ в МЕТАДАННЫХ СТАТЬИ (НTML-КОД):

$<$ a rel="license" href="http://creativecommons.org/licenses/by/4.0/"><img alt="Лицензия Creative Commons" style="borderwidth:0" src="https://i.creativecommons.org/l/by/4.0/88x31.png" / ></a $><$ br $/>$ Произведение "<span xmlns:dct="http:// purl.org/dc/terms/" href="http://purl.org/dc/dcmitype/Text" property="dct:title" rel="dct:type">Углерод в конденсированных углеводородных фазах, сталях и чугунах $</$ span $>$ » созданное автором по имени $<$ a xmlns:cc="http://creativecommons. org/ns\#" href="Нанотехнологии в строительстве. - 2017. - Том 9, № 6. - С. 111-128. - DOI: dx.doi.org/10.15828/2075-85452017-9-6-111-128." property="cc:attributionName" rel="cc:attributionURL" > Гафарова В.А. </a $>$, публикуется на условиях $<$ a rel="license" href="http://creativecommons.org/licenses/by/4.0/">лицензии Creative Commons "Attribution» ("Атрибуция») 4.0 Всемирная $</ \mathrm{a}>$. $<$ br $/>$ Основано на произведении с $<$ a xmlns:dct="http://purl.org/dc/terms/" href="http://nanobuild. ru/ru RU/nanobuild-6-2017/" rel="dct:source">http://nanobuild.ru/ru RU/nanobuild-6-2017/</a>.<br />Pазрешения, выходящие за рамки данной лицензии, могут быть доступны на странице $<$ a xmlns:cc="http://creativecommons.org/ns\#" href="gafarova.vika@bk.ru" rel="cc:morePermissions">gafarova.vika@bk.ru</a> .

\section{Введение}

Уникальные свойства углерода [1] поставили его в центр наиболее важных процессов, происходящих в окружающей среде и в технике. Углерод имеет три изотопа и конфигурацию электронного состояния, позволяющую иметь различное количество валентных электронов. Это позволяет создавать различные пространственные формы углерода, известные как графит, алмаз, карбин, фуллерен, углеродные нанотрубки [2]. В то же время соединения с водородом позволяют создать огромное количество углеводородов с различными свойствами и областью применения. Углерод принимает участие в различных технологиях получения металлов из руды в качестве электропроводящего материала, теплоносителя. Так, в сталях и чугунах углерод, присутствуя в неболь- 
ших количествах, существенно изменяет физико-механические свойства конструкционных материалов. Технически чистое железо (армкожелезо, карбонильное железо) - пластичный материал, который может применяться в качестве уплотнительного материала во фланцевых соединениях аппаратов, работающих под высоким давлением. В то же время содержание углерода в матрице железа более $0,1 \%$ позволяет получить стали и чугуны с высокими показателями прочности. Углерод с металлами образует карбиды или соединения, которые идентифицируются как цементит. Хотя общая формула цементита $\mathrm{Fe} 3 \mathrm{C}$, имеются сведения, которые ставят под сомнение реализацию такой формулы. Механизмы связи углерода с металлами сложны и разнообразны. Расположение его в феррите, аустените, мартенсите носит сложный и не всегда однозначный характер [3]. Все это привлекает внимание исследователей, поскольку углерод в своих различных проявлениях приносит неожиданные открытия, часть из которых будут объектом настоящего обзора.

\section{Конденсированные углеводороды}

При последовательной термической переработке углеводородного сырья образуются высокомолекулярные углеводороды, которые уменьшают выход светлых нефтепродуктов. На каждом переделе образуются остатки типа мазута, гудрона, остатки различных процессов крекинга, нефтяные пеки, и в конце всех переделов получают нефтяной кокс, содержащий более $90 \%$ углерода [4]. Нефтяные пеки и коксы имеют аналоги, полученные из каменных углей, и их применяют в ряде случаев совместно. Однако продукты, полученные из нефтяного сырья, имеют нестабильный состав и хуже графитируются при высоких температуpax. При получении и дальнейшем использовании пеков происходит их взаимодействие с металлом конструкций, в которых происходят процессы. В частности, имеет место адгезионное взаимодействие, которое осложняет технологический процесс. При изучении закономерностей адгезии каменноугольного пека к металлической поверхности были обнаружены структуры, которые не соответствовали тем представлениям, которые сложились о природе и свойствах пеков (рис. 1). Пек - это вещество, в составе которого могут быть идентифицированы несколько тысяч индивидуальных углеводородов, поэтому пек считается аморф- 


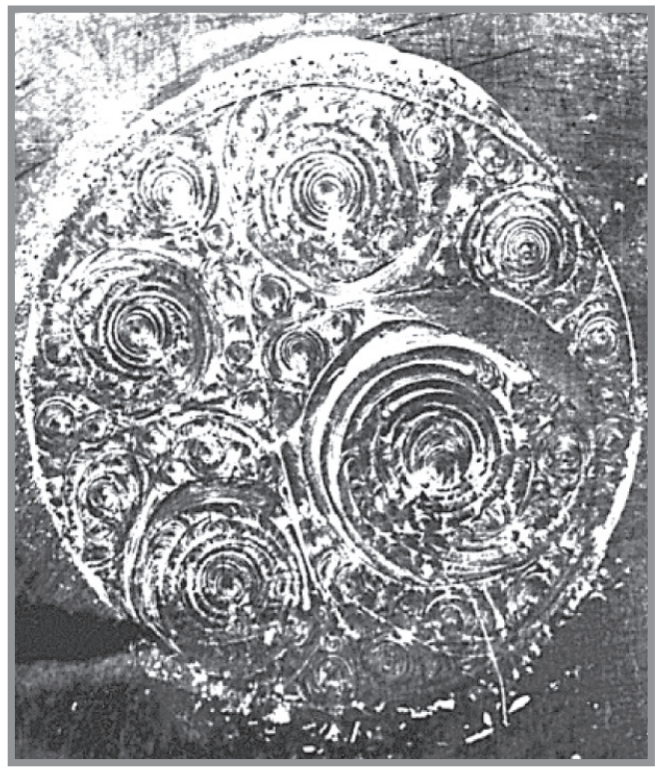

Рис. 1. Спиралевидные структуры в пеке

ным стеклоподобным веществом. Обнаружение упорядоченных структур, которые представляли собой спиралевидные образования, потребовало по новому взглянуть на понятие кристалличности [5]. Наличие большого количества углеводородов различной конфигурации в пеках подсказывает, что структурирование в макромасштабе возможно при двух условиях:

- $\quad$ должна создаваться иерархия структур, как это показано на рис. 2;

- должен существовать некий управляющий параметр процесса структурирования.

Таким управляющим параметром для нефтяных систем является наличие парамагнитных соединений [7], которые образуются в процессе термических превращений и характеризуются некомпенсированным спином валентных электронов. В частности, оценено, что парамагнетизм, измеренный в единицах спин/грамм, для бензинов $10^{15}$, для нефтей $10^{17}-10^{18}$, асфальтенов $10^{19}-10^{21}$, для карбенов и карбоидов $10^{20}-10^{22}$.

Некомпенсированные спины, стремясь к компенсации, заставляют составляющие пеков концентрироваться и уплотняться. Однако полной компенсации не возникает из-за стерических затруднений.

Для выяснения такого предположения были поставлены эксперименты с применением радиоактивного углерода $\mathrm{C}^{14}$, который по опреде- 


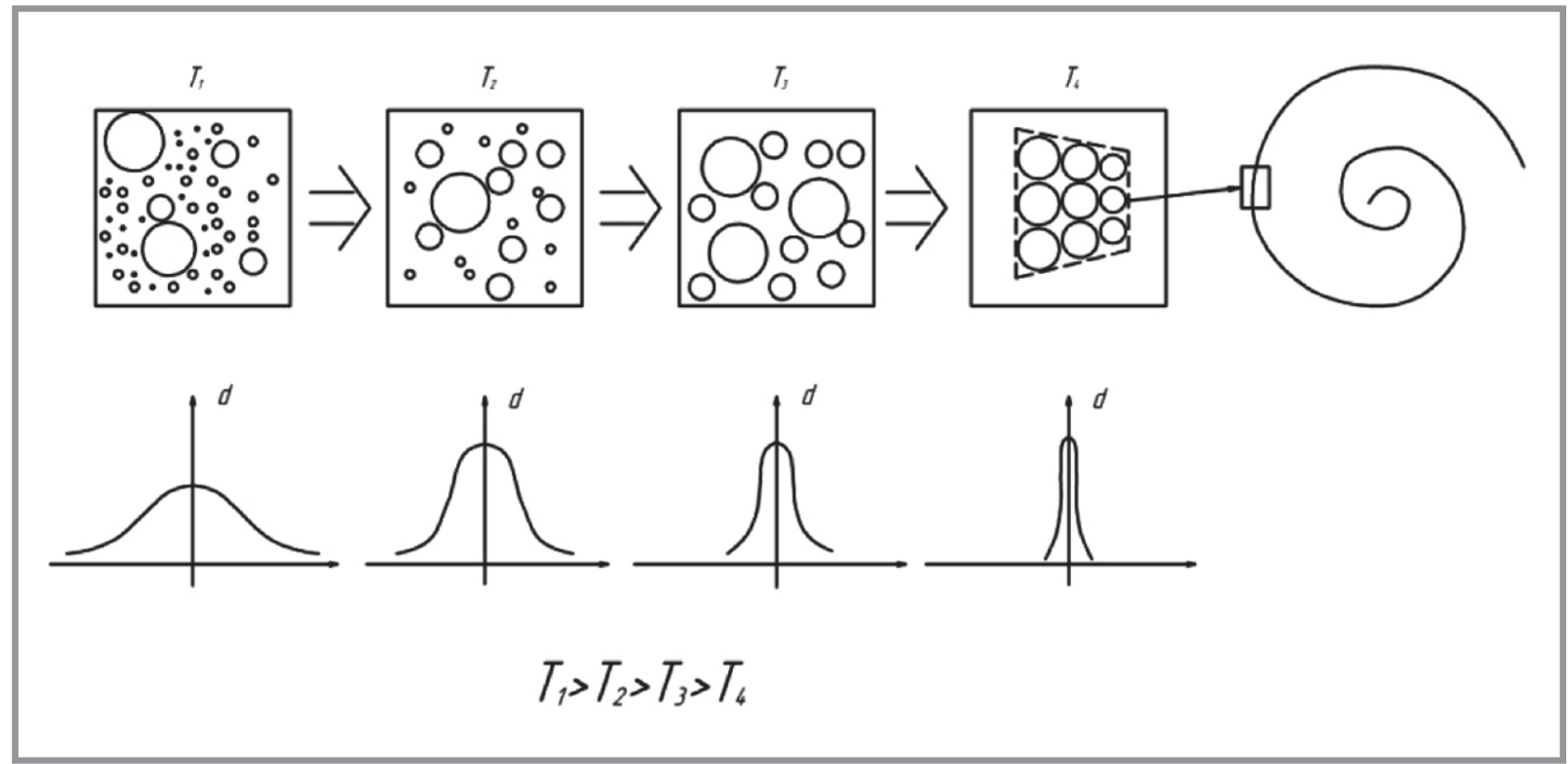

Рuc. 2. Схема иерархического структурирования пека [6]

ленной технологии внедрялся в различные углеводороды, которые подвергались термолизу [8-12] с образованием пековой фазы. Выяснилось, что основу спиральной структуры составляют карбоиды [8], которые идентифицируются как вещества с высоким содержанием углерода и не растворимые в органических растворителях.

Иерархическое структурирование при термолизе углеводородов и образование пеков указывает на то, что у возникающих кластеров имеются пределы роста. В связи с этим возникла идея о фрактальной структуре кластеров [13], которая легла в основу моделирования структуры кластеров с использованием метода Виттена-Сандера. При этом оказалось, что спиралевидные структуры возникают в моделях случайного блуждания, только при наложении вращательной компоненты. Эти идеи были развиты при дальнейших исследованиях пеков, и была доказана фрактальная организация иерархических структур $[12,14,15]$.

При дальнейшем термолизе пековой фазы на поверхности металла образовывался кокс, в котором сохранялся углерод $\mathrm{C}^{14}$. При дальнейшем повышении температуры в системе кокс-металл обнаружилось проникновение углерода из кокса в металл, поскольку в металле обнаружился радиоактивный углерод [16]. 


\section{Идентификация фуллеренов в сталях и чугунах}

Проникновение углерода в металл из кокса и факт незначительного растворения углерода в $\alpha-\mathrm{Fe}$ позволили предположить возможность локальной концентрации углерода в значительных количествах перед фронтом кристаллизации в границах зерен, в порах, и образования молекулярной формы углерода - фуллеренов, экспериментальное подтверждение существования которых было опубликовано в работе [17]. Реальность такого события была настолько велика, что была построена модель системы железо-углерод, и начались разработки метода выделения фуллеренов из сталей и чугунов $[18,19]$. При высокотемпературном испарении углерода с поверхности графита идентифицируются масс-спектры фуллеренов с различным содержанием углерода (рис. 3) [20]. Поэтому в первую очередь при попытках выделения фуллеренов из стали и чугуна необходимо было получить масс-спектры экстрактов, полученных при растворении сталей и чугунов в плавиковой кислоте. Такие спектры были получены (рис. 4) [21], в которых идентифицируются спектры фуллеренов $\mathrm{C}_{60}$ и $\mathrm{C}_{70}$, а также их фторированные производные. Необходимо отметить, что попытки растворить матрицу железа смесью азотной и соляной кислот привели к отрицательному результату, поскольку эта смесь разрушала фуллерены на определенные фрагменты.

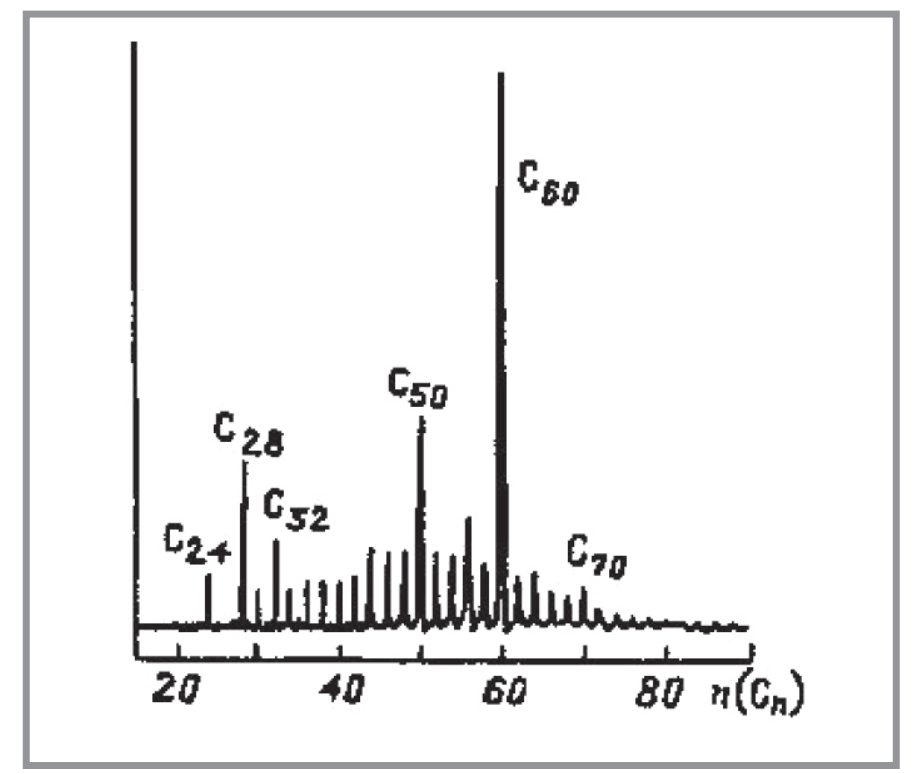

Рuc. 3. Масс-спектр продуктов термического испарения графита [20] 


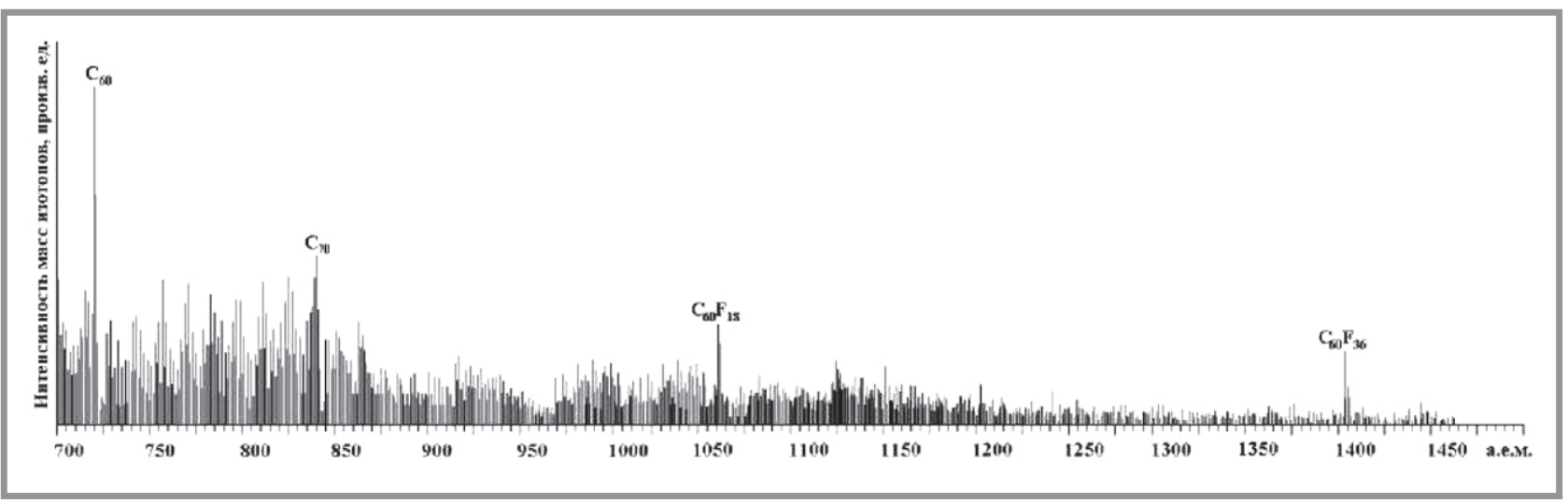

Puc. 4. Масс-спектр экстракта серого чугуна СЧ18 [21]

Также были получены ИК-спектры, в которых идентифицировались характерные для фуллеренов $\mathrm{C}_{60}$ четыре пика $[21,22]$. По интенсивности пиков в ИК-спектрах с помощью тарировочных графиков, полученных на чистых фуллеренах, удалось количественно описать распределение фуллеренов в сталях и чугунах. В дальнейшем фуллерены были идентифицированы в сталях и чугунах после растворения структуры железа в плавиковой кислоте с помощью жидкостной хроматографии, сканирующей туннельной микроскопии [23].

Разработка метода количественного определения фуллеренов, выделенных из структуры сталей и чугунов, позволила расширить исследования и обратить внимание на различные стадии получения чугунов. Фуллерены были обнаружены в структуре чугунов при первичной кристаллизации и доменном процессе $[24,25]$. Полученные результаты подтвердили разработанную ранее модель образования фуллеренов в матрице железа [19, 23].

Дальнейшие исследования были направлены на изучение возможности образования фуллеренов в матрице поликристаллического железа при внедрении углерода извне. Фуллерены $\mathrm{C}_{60}$ и $\mathrm{C}_{70}$ формируются в сталях при внедрении углерода из газовой фазы при цементации [26] и в результате внедрения углерода из отложившегося на поверхности металла кокса [27]. Эти результаты показали принципиальную возможность создания поверхностного слоя, насыщенного фуллеренами, что было продемонстрировано в работах по созданию фуллеренового слоя с использованием карбоната бария и нефтяного пека [28]. При этом показано, что создание модифицированного слоя с повышенным содержа- 
нием фуллеренов позволило повысить антикоррозионные и трибологические свойства сталей 20 и ШХ15 [29, 30].

Представляют практический интерес сравнительные исследования содержания фуллеренов и распределения микротвердости в различных зонах сварных соединений из стали 20 [31, 32]. Характер изменения количества фуллеренов и микротвердости оказался идентичным. Показано, что движение фронта кристаллизации при формировании сварного шва из расплава приводит к повышению концентрации углерода на границе затвердевания и созданию благоприятных условий для образования фуллеренов.

Проникновение углерода в металл из отложившегося на поверхности кокса создает трудности при эксплуатации оборудования, поскольку внедрение дополнительного количества углерода изменяет механические свойства конструкционного материала [33, 34]. В связи с этим происходит перераспределение механических напряжений в конструкциях и непредвиденные разрушения в виде трещин. Поэтому исследуются способы предотвращения диффузии углерода в металл, например, за счет пассивирования поверхности кремнием [35].

Трудности в изучении и количественном анализе фуллеренов в сталях и чугунах заключаются в том, что способ их идентификации и определения количества весьма трудоемкий. Согласно [36] требуется предварительная обработка металлического образца плавиковой кислотой с целью растворения металлической матрицы. Затем из раствора получают осадок и высушивают его и измельчают. Для измерений, проводимых на ИК-спектрометре, полученный осадок смешивают с бромидом калия и изготавливают таблетки методом холодного прессования. Для количественного определения содержания фуллеренов необходимо иметь тарировочные зависимости. Сложная подготовка проб при идентификации фуллеренов в сталях затрудняет проведения интенсивных исследований в этом направлении и требует поиска экспресс-методов количественного анализа. Предпосылки для создания экспресс-метода заключаются в некоторых особенностях магнитных свойств фуллеренов [37].

\section{Заключение}

Обзор исследований, направленных на выявление новых закономерностей в поведении углерода в конденсированных углеводородных 
фазах, сталях и чугунах, указывает на необходимость продолжения исследований с использованием современного оборудования и выявления способов экспресс-анализа количества фуллеренов в сплошных фазах без разрушения последних.

Исследования проводятся в Урилскол государственнол нефтянол техническол университете в ралках реализации инициативного научного проекта фундалентального характера по государственнолу заданию образовательным учреждениял высшего образования на 2017-2019 г2. (№ 9.7294.2017/8.9 от 31.01.2017) при содействии Межвузовского центра коллективного пользования "Региональный научно-производственный колплекс «Недра"».

\section{Библиографический список:}

1. Фиалков А.С. Углерод, межслоевые соединения и композиты на его основе. М.: Аспект Пресс, 1997. - 718 с.

2. Сидоров Л.Н., Юровская М.А., Боршевский А.Я., Трушков И.В., Иоффе И.Н. Фуллерены. - М.: Издательство «Экзамен», 2005. - 688 с.

3. Гаврилюк В.Г. Распределение углерода в стали. - Киев: Наук. думка, 1987. $208 \mathrm{c}$.

4. Гилаев Р.Н., Кузеев И.Р., Абызгильдин Ю.М. Нефтяной кокс. - Москва, 1992. $80 \mathrm{c.}$

5. Kuzeev I.R. Crystallization of petroleum carbon on metal surface / I.R. Kuzeev, R.G. Sharafiev, Yu.M. Abyzgil'din, M.V. Kretinin // Chemistry and Technology of Fuels and Oils. - 1984. - T. 20. - № 1. - C. 29-32.

6. Баязитов М.И. Формирование признаков кристаллических тел в потенциально аморфных системах / М.И. Баязитов, А.Н. Васильев, В.А. Гафарова, И.Р. Кузеев, Д.К. Никифорова // Известия высших учебных заведений. Нефть и газ. - 2014. - № 5. - С. 82-86.

7. Андреева Л.Н. Физика образования коллоидов нефтяных дисперсных систем. Элементы спиновой химии / Л.Н. Андреева, С.Я. Александрова, Л.В. Цыро, Ф.Г. Унгер // Известия высших учебных заведений. Нефть и газ. - 2009. № 4. - С. 101-107.

8. Кузеев И.Р. Состав спиралевидных структур при кристаллизации нефтяного углерода на поверхности металла / И.Р. Кузеев, И.Р. Хайрутдинов, И.Г. Ибра- 
гимов, Ю.М. Абызгильдин, Р.Л. Хабибуллин // Химия и технология топлив и масел. - 1984. - № 11. - С. 29.

9. Kuzeev I.R. Composition of helical structures in crystallization in petroleum carbon on a metal surface / I.R. Kuzeev, I.R. Khairudinov, I.G. Ibragimov, Yu.M. Abyzgil'din, R.L. Khabibullin // Chemistry and Technology of Fuels and Oils. - 1985. - T. 20. - № 11. - C. 559-561.

10. Хайрудинов И.Р. Состав отложений коксосмолистых продуктов на металлической поверхности / И.Р. Хайрудинов, И.Р. Кузеев, И.Г. Ибрагимов, Ф.Г. Унгер // Известия высших учебных заведений. Серия: Химия и химическая технология. - 1986. - Т. 29. - № 12. - С. 47-51.

11. Кузеев И.Р. Формирование нефтяных углеродистых веществ и их взаимодействие с металлической поверхностью / И.Р. Кузеев, И.Р. Хайрутдинов, Ю.М. Абызгильдин // Химия твердого топлива. - 1987. - № 2. - С. 142.

12. Мухалетзянов И.З. Фрактальные структуры при карбонизации нефтяного сырья / И.З. Мухаметзянов, И.Р .Кузеев, Ю.М. Абызгильдин // Химия твердого топлива. - 1990. - № 6. - С. 91-94.

13. Kulikov D.V. Solid petroleum residue as macroscopic model systems for the study of microstructure in metal materials / D.V. Kulikov, I.R. Kuzeev / Materials Science and Engineering: A. - 1997. - T. 234-236. - C. 949-952.

14. Кузеев И.Р. Фрактальная структура парамагнитных агрегатов нефтяных пеков / И.Р. Кузеев, И.З. Мухаметзянов // Коллоидный журнал. - 1991. - Т. 53, № $4 .-$ С. $762-766$.

15. Mukhametzyanov I.Z. Structural organization of petroleum disperse systems / I.Z. Mukhametzyanov, I.R. Kuzeev, V.G. Voronov, S.I. Spivak // Doklady Physical Chemistry. - 2002. - T. 387. - № 1-3. - C. 284-286.

16. Кузеев И.Р. Особенности диффузии углерода из нефтяного кокса в металл / И.Р. Кузеев, И.Г. Ибрагимов, М.И. Баязитов, И.Р. Хайрудинов // Химия и технология топлив и масел. - 1986. - № 6. - С. 13-14.

17. Kroto H.W. Buckminsterfullerene / H.W. Kroto, J.R. Heath, S.C. O'Brien, R.F. Curl \& R.E. C. Smalley // Nature 318:162-3. - 1985.

18. Закирничная M.M. Определение формы свободного углерода в углеродистых сплавах / М.М. Закирничная, И.Р. Кузеев // XXXXVII Научно-техническая конференция студентов, аспирантов и молодых ученых. - 1996. - С. 166.

19. Кузеев И.Р. Фуллеренная модель структуры железо-углеродистых сплавов / И.Р. Кузеев, М.М. Закирничная, Г.Х. Самигуллин, Н.В. Мекалова // Синергетика, структура и свойства материалов, самоорганизующиеся технологии. Симпозиум. - 1996. - С. 208. 
20. Cox D.M., Reichmann K.C., Kaldor A.P. // Chem. Soc. 1988. V. I 10. P. 1588.

21. Иванова В.С. Фуллерены в чугуне / В.С. Иванова, И.Р. Кузеев, М.М. Закирничная // Материаловедение. - 1998. - № 2. - С. 5-14.

22. Иванова В.С. О самоподобии фуллеренов, образующегося в структурах продуктов термического испарения графита, шунгита и высокоуглеродистой стали / В.С. Иванова, И.Р. Кузеев, Д.В. Козицкий, М.М. Закирничная // Перспективные материалы. - 1998. - № 1. - С. 5-15.

23. Закирничная M.M. Образование фуллеренов в углеродистых сталях и чугунах при кристаллизации и термических воздействиях. - Уфа: «Гилем», 2002. - 180 с.

24. Кузеев И.Р. Образование фуллеренов в структуре чугунов при первичной кристаллизации и доменном процессе / И.Р. Кузеев, М.М. Закирничная, Д.А. Годовский // Фракталы и прикладная синергетика. Труды Международного междисциплинарного симпозиума. - 1999. - С. 187-189.

25. Закирничная M.M. Миграция и образование фуллереновых структур на различных стадиях получения железо-углеродистых сплавов / М.М. Закирничная, И.Р. Кузеев, В.М. Корнилов, А.Н. Лачинов // Геология. Известия Отделения наук о Земле и природных ресурсов. - Академия наук Республики Башкортостан. - 2001. - № 6. - С. 39-49.

26. Кузеев И.Р. Изучение фуллеренов в науглероженном слое, полученном при цементации / И.Р. Кузеев, М.М. Закирничная, О.И. Ткаченко, Д.А. Годовский // Техника на пороге XXI века. - Уфа. - 1999. - С. 176-177.

27. Закирничная M.M. Изменение структуры и свойств металла труб змеевиков печей пиролиза в процессе эксплуатации / М.М. Закирничная, А.Г. Чиркова, И.Р. Кузеев // Известия высших учебных заведений. Нефть и газ. - 1998. № 2. - С. 87-92.

28. Никифорова Д.К. Изменение физико-механических свойств стали при диффузионном насыщении углеродом поверхностного слоя / Д.К. Никифорова, В.А. Гафарова, В.В. Васильев, И.Р. Кузеев // Промышленная безопасность на взрывопожароопасных и химически опасных производственных объектах. Материалы VIII научно-практической конференции. - 2014. - С. 158-160.

29. Кузеев И.Р. Модифицирование поверхностного слоя стали 20 с помощью фуллеренов / И.Р. Кузеев, С.В. Попова, М.Р. Гималова // Нефтегазовое дело. 2012. - T. 10, № 1. - С. 185-190.

30. Габдуллина М.Р. Формирование металлофуллеренового поверхностного слоя с целью пассивации поверхности в углеродистых сталях / M.Р. Габдуллина, И.Р. Кузеев, Д.К. Никифорова, М.Ф. Габдуллин // Нефтегазовое дело. 2014. - № 3. - С. 310-328. 
31. Закирничная M.M. Распределение фуллеренов по зонам сварного соединения / М.М. Закирничная, И.Р. Кузеев, О.И. Ткаченко // Сварочное производство. 1999. - № 11. - С. 23.

32. Закирничная M.M. Образование фуллеренов в процессе диффузии углерода в структуру стали / М.М. Закирничная, И.Р. Кузеев, О.И. Ткаченко // Известия высших учебных заведений. Нефть и газ. - 2012. - №2. - С. 112-119.

33. Чиркова А.Г. Изменение напряженно-деформированного состояния змеевиков печей пиролиза в процессе эксплуатации / А.Г. Чиркова, И.Р. Кузеев, С.В. Попова, А.Н. Васильев // Башкирский химический журнал. - 2011. - Т. 18. № $1 .-$ C. $78-82$.

34. Кузеев И.Р. Изучение закономерности диффузии углерода в поверхностный слой стали 12Х18Н10Т / И.Р. Кузеев, С.В. Попова, А.Н. Васильев // Литье и металлургия. - 2012. - № 3. - С. 346-348.

35. Хисаева З.Ф. Модифицирование поверхности змеевиков трубчатых печей для защиты от науглероживания и коксообразования / З.Ф. Хисаева, И.Р. Кузеев // Нефтегазовое дело. - 2003. - № 2. - С. 13.

36. Кузеев И.Р., Попова С.В., Савичева Ю.Н. Способ идентификации фуллеренов $\mathrm{C}_{60}$ и $\mathrm{C}_{70}$ в сталях и чугунах // Патент РФ 2411182. 08.07.2009.

37. Макарова Т.Л. Магнитные свойства углеродных структур // Физика и техника полупроводников. - 2004. - Т. 38, Вып. 6. - С. 641-664.

\section{УВАЖАЕМЫЕ КОЛЛЕГИ! \\ ПРИ ИСПОЛЬЗОВАНИИ МАТЕРИАЛА ДАННОЙ СТАТЬИ \\ ПРОСИМ ДЕЛАТЬ БИБЛИОГРАФИЧЕСКУЮ ССЫЛКУ НА НЕЁ:}

Гафарова B.A. Углерод в конденсированных углеводородных фазах, сталях и чугунах // Нанотехнологии в строительстве. - 2017. - Том 9, № 6. - С. 111128. - DOI: dx.doi.org/10.15828/2075-8545-2017-9-6-111-128.

\section{DeAR COlleagues!}

THE REFERENCE TO THIS PAPER HAS THE FOLLOWING CITATION FORMAT:

Gafarova V.A. Carbon in condensed hydrocarbon phases, steels and cast irons. Nanotehnologii v stroitel'stve $=$ Nanotechnologies in Construction. 2017, Vol. 9, no. 6, pp. 111-128. DOI: dx.doi.org/10.15828/2075-8545-2017-9-6-111-128. (In Russian). 